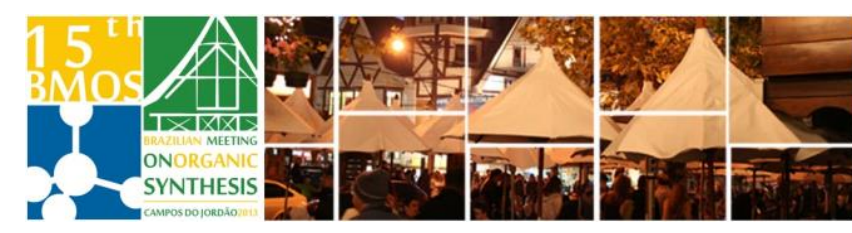

\title{
New one-pot and regioselective method for the synthesis of 3-trifluoromethyl-1H-1-phenylpyrazoles
}

\author{
Everton P. Pittaluga (PG) ${ }^{1}$, Helio G. Bonacorso $(P Q)^{* 1}$, Michele S. Correa $(P Q)^{2}$, \\ Liliane M. F. Porte (PQ) ${ }^{1}$, Andrizia F. Junges (IC) ${ }^{1}$, Marcos A. P. Martins (PQ) ${ }^{1}$, Nilo \\ Zanatta (PQ) \\ ${ }^{1}$ Núcleo de Química de Heterociclos (NUQUIMHE), Departamento de Química, Universidade Federal de \\ Santa Maria, 97105-900, Santa Maria, RS - Brazil. \\ ${ }^{2}$ Universidade Federal Do Pampa - Campus São Gabriel 97300-000, São Gabriel, RS - Brazil.
}

${ }^{\star} E$-mail heliogb@base.ufsm.br (H.G. Bonacorso)

Keywords: 3-Trifluoromethylpyrazoles, Cyclization reactions, Phenylsemicarbazides

\section{INTRODUCTION}

Pyrazoles derivatives has been extensively explored by our research group contemplating their biological activities. ${ }^{1}$ Efficient approaches to introduce a $\mathrm{CF}_{3}$ group at the $\mathrm{C}-3$ position of pyrazole ring in a regioselective manner has been getting attention, mostly because these compounds often show pharmacological activities such as the antiinflammatory Celecoxib ${ }^{\circledR}$ and the anticoagulant Razaxaban ${ }^{\circledR}$ and the anticoagulant Razaxaban ${ }^{\circledR}$. So, we report an efficient and regioselective insertion of a $\mathrm{CF}_{3}$ group into pyrazole rings from the reaction of 4-alkoxy-1,1,1-trifluoroalk-3-en-2-ones $\left[\mathrm{CF}_{3} \mathrm{C}(\mathrm{O}) \mathrm{CH}\right.$ $=\mathrm{CR}^{1}(\mathrm{OR})$ where $\mathrm{R}=\mathrm{Me}$ or $\mathrm{Et}, \mathrm{R}^{1}=\mathrm{H}, \mathrm{Me}, \mathrm{Ph}$, 2-Furyl and $R^{1}-R^{2}=-C_{4} H_{8}$ - (1a-e) and 1-phenylsemicarbazide (2) in order to obtain 3-trifluoromethyl-1-phenylpyrazoles (3a-e) as the main isomer.

\section{RESULTS AND DISCUSSION}

The optimized synthesis of 3-trifluoromethyl pyrazoles (3a-e) was carried-out in the presence of sulfuric acid and methanol as the reaction solvent and in a 1:1.5 molar ratio (1a-e:2), stirring the mixtures at $60{ }^{\circ} \mathrm{C}$ for $24 \mathrm{~h}$ (Scheme 1). ${ }^{2}$ All 3a-e structures were confirmed by ${ }^{1} \mathrm{H}$ and ${ }^{13} \mathrm{C}$ NMR and mass spectrometry (GC-MS) data analysis and by comparison to the 5-trifluormethyl-1H-pyrazole isomers previously acquired. ${ }^{3}$

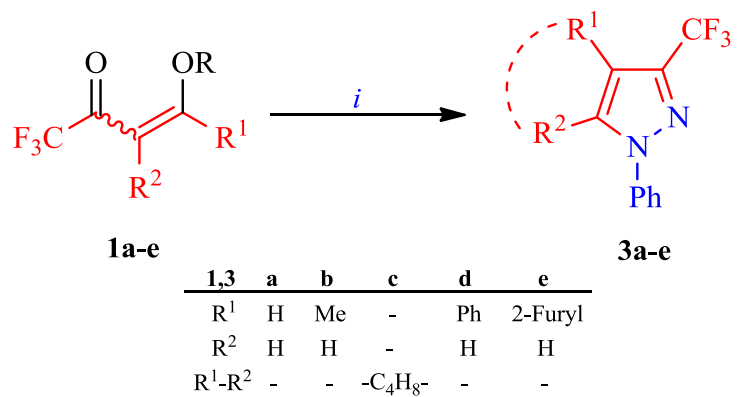

Scheme 1. Reagents and conditions: (I) $\mathrm{Ph}(\mathrm{NH})_{2} \mathrm{CONH}_{2}$ (2), $\mathrm{MeOH}, \mathrm{H}_{2} \mathrm{SO}_{4}$ conc., $60^{\circ} \mathrm{C}, 24 \mathrm{~h}(50-85 \%)$.
Thus, we identified and easily proved that the $3-\mathrm{CF}_{3}$ substituted pyrazole regioisomers were isolated through this new present methodology (Table 1).

Table 1. Yields and isomer relations for compouds 3a-e.

\begin{tabular}{ccc}
\hline Product & ${\text { Yield }(\%)^{\mathrm{a}} /\left(\text { Lit. }^{\mathrm{b}}\right.}^{\mathrm{b}}$ & Isomer 1,3:1,5 $^{\mathrm{c}} /$ (Lit. $^{\mathrm{b}}$ \\
\hline 3a & $50 /(16),(94)$ & $50: 50 /(100: 0)$ \\
3b & $77 /(70),(80)$ & $100: 0 /(50: 50)$ \\
3c & 54 & $97: 3$ \\
3d & $65 /\left(-^{\mathrm{d}}\right),(65)$ & $100: 0 /(82: 18),(100: 0)$ \\
3e & $85 /\left({ }^{\mathrm{d}}\right)$ & $100: 0 /(100: 0)$ \\
\hline
\end{tabular}

${ }^{a}$ Yields of isolated products. ${ }^{b}$ Literature data. ${ }^{\mathrm{c}} \mathrm{GC}-\mathrm{MS}$ data analysis. ${ }^{\mathrm{d}}$ Uninformed yields from literature data.

\section{CONCLUSION}

We have developed a mild, convenient and improved protocol for the regioselective synthesis of 3-trifluoromethyl-1 $\mathrm{H}$-1-phenylpyrazoles in methanol and sulfuric acid as catalyst. This new method is simple and efficient for achievement of regionselective products. Compounds 3a-e were obtained as dark-yellow oils in $50-85 \%$ yields. Complete results are covered in our patent and in a recent published paper. $^{2}$

\section{ACKNOWLEDGEMENTS}

\section{CNPq - CAPES}

\section{REFERENCES}

${ }^{1}$ (a)Bonacorso, H. G.; Pittaluga, E. P.; Alves, S. H.; Schaffer, L. F.; Cavinatto, S.; Porte, L. M. F.; Paim, G. R.; Martins, M. A. P.; Zanatta, N. ARKIVOC 2012, viii, 62; (b) Bonacorso, H. G.; Cavinatto, S.; Campos, P. T.; Porte, L. M. F.; Navarini, J.; Paim, G. R.; Martins, M. A. P.; Zanatta, N.; Stuker, C. Z. J. Fluorine Chem. 2012, 135, 303.

${ }^{2}$ (a) Bonacorso, H. G.; Correa, M. S.; Porte, L. M. F.; Martins, M. A. P. Zanatta, N. BR Patent deposited on National Institute for Industrial Property - INPI (PI1105807-2) in agreement to Federal University of Santa Maria, 2011; (b) Bonacorso, H. G.; Correa, M. S.; Porte, L. M. F.; Pittaluga, E. P.; Martins, M. A. P.; Zanatta, N. Tetrahedron Lett. 2012, 53, 5488.

${ }^{3}$ Braibante, M. E. F.; Clar, G.; Martins, M. A. P. J. Heterocycl. Chem. 1993, 30, 1159. 